\title{
Cell plasticity in wound healing: paracrine factors of M1/ M2 polarized macrophages influence the phenotypical state of dermal fibroblasts
}

\author{
Diana TA Ploeger ${ }^{*}$, Nynke A Hosper ${ }^{\dagger}$, Martin Schipper, Jasper A Koerts, Saskia de Rond and Ruud A Bank
}

\begin{abstract}
Background: Macrophages and fibroblasts are two major players in tissue repair and fibrosis. Despite the relevance of macrophages and fibroblasts in tissue homeostasis, remarkably little is known whether macrophages are able to influence the properties of fibroblasts. Here we investigated the role of paracrine factors secreted by classically activated (M1) and alternatively activated (M2) human macrophages on human dermal fibroblasts (HDFs).

Results: HDFs stimulated with paracrine factors from M1 macrophages showed a 10 to > 100-fold increase in the expression of the inflammatory cytokines IL6, CCL2 and CCL7 and the matrix metalloproteinases MMP1 and MMP3. This indicates that factors produced by M1 macrophages induce a fibroblast phenotype with pro-inflammatory and extracellular matrix (ECM) degrading properties. HDFs stimulated with paracrine factors secreted by M2 macrophages displayed an increased proliferation rate. Interestingly, the M1-activated pro-inflammatory fibroblasts downregulated, after exposure to paracrine factors produced by M2 macrophages or non-conditioned media, the inflammatory markers as well as MMPs and upregulated their collagen production.
\end{abstract}

Conclusions: Paracrine factors of M1 or M2 polarized macrophages induced different phenotypes of HDFs and the HDF phenotypes can in turn be reversed, pointing to a high dynamic plasticity of fibroblasts in the different phases of tissue repair.

Keywords: Cell plasticity, Classically/alternatively activated macrophages, Extracellular matrix remodeling, Inflammation, Matrix metalloproteinases, Paracrine signaling, Primary human dermal fibroblasts

\section{Background}

In wound healing and fibrosis, a variety of processes are crucial, such as inflammation, cell proliferation, cell migration and extracellular matrix (ECM) remodeling. Two major cellular players in these processes are macrophages and fibroblasts [1-4]. During the proliferation phase of wound healing, fibroblasts proliferate and migrate into the wound site to form granulation tissue. Part of these fibroblasts differentiate into myofibroblasts and produce new ECM, mainly in the form of collagen, which is necessary to support cellular ingrowth. The degradation of collagen in the wound is mainly controlled by matrix metalloproteinases (MMPs). In normal

\footnotetext{
*Correspondence: d.t.a.ploeger@umcg.nl

${ }^{\dagger}$ Equal contributors

Department of Pathology and Medical Biology, Medical Biology Section, University Medical Center Groningen, University of Groningen, Hanzeplein 1 Groningen 9713 GZ, The Netherlands
}

(c) 2013 Ploeger et al.; licensee BioMed Central Ltd. This is an Open Access article distributed under the terms of the Creative Commons Attribution License (http://creativecommons.org/licenses/by/2.0), which permits unrestricted use, distribution, and reproduction in any medium, provided the original work is properly cited.

wound healing, most of the myofibroblasts and fibroblasts go into apoptosis in due time, or leave the wound site. However, in fibrosis myofibroblasts accumulate and produce an excess of collagen that remains deposited, thereby causing damage to the tissue architecture and diminishing its function [5-9].

The other important cell type in wound healing and fibrosis, macrophages, exist as resident tissue-specific macrophages, or are derived from circulating blood monocytes that undergo diapedesis and subsequently differentiate into macrophages. Macrophages display various activation states. The two opposite activation states are known as classically activated (M1) and alternatively activated (M2) macrophages [10,11]. The M1 macrophage is pro-inflammatory and is often associated with tissue injury and inflammation, whereas the M2 macrophage is associated with tissue repair and fibrosis [12-15]. Factors that induce the M1 polarization of 
macrophages are interferon gamma (INFG), tumor necrosis factor (TNF), and/or lipopolysaccharides (LPS), whereas M2 macrophage polarization is induced by interleukin 4 (IL4), 13 (IL13), 10 (IL10), glucocorticoids and/or transforming growth factor beta 1 (TGFB1) $[11,16,17]$.

In the inflammatory phase of wound healing, invading macrophages are pro-inflammatory (M1) and secrete several cytokines and chemokines, like chemokine (C-C motif) ligand 2 (CCL2) (monocyte chemotactic protein-1), CCL7 (monocyte chemotactic protein-3) and interleukin 6 (IL6). These cytokines/chemokines play a crucial role in wound healing and are involved in fibrogenesis [13, 15,18-21]. M2 macrophages are associated with the healing process by modulating the inflammatory process and by secreting factors like CCL18. CCL18 is able to stimulate fibroblast proliferation and collagen production, which are important in the healing process, but an increased CCL18 expression can also induce fibrosis [22,23].

It has been shown that macrophages show a high dynamic plasticity. Macrophages can change, depending on the stimulus in the micro-environment, their secretion pattern of cytokines and chemokines several times [24-26]. For example, human primary M1 polarized macrophages can be re-polarized by secreted factors from their own counterparts, M2 macrophages, and vice versa, in vitro [27]. In vivo, there are indications that repolarization of macrophages also occurs, as shown in a mouse model for atherosclerosis [28] and in a rodent model for myocardial infarction [29]. This macrophage plasticity not only has an effect on the inflammation phase of wound healing, but likely also on the proliferation and remodeling phase.

Despite the relevance of macrophages and fibroblasts in tissue homeostasis, remarkably little is known whether the different types of human primary macrophages are able to influence directly the properties of human primary fibroblasts. Most of the data found in literature have generally been generated with cell lines [30-32] or primary cells from murine origin [33,34], mostly without paying attention to the M1/M2 activation state. Here we investigated the role of paracrine factors secreted by human M1 and M2 macrophages on primary adult human dermal fibroblasts (HDFs) with respect to proliferation, myofibroblast formation, collagen synthesis and degradation, as well as synthesis of various cytokines. Because of the plasticity of macrophages, we also set out to investigate the influence of paracrine factors secreted by M1 macrophages followed by paracrine factors secreted by M2 macrophages on HDFs.

\section{Results}

Characterization of macrophages after M1 or M2 polarization Primary human macrophages responded to LPS/IFNG or IL4/IL13, resulting in M1 or M2 polarization, respectively. M1 polarized macrophages adopted a "dendritic"-like morphology with large filopodia while M2 polarized macrophages showed a rounded and/or spindleshaped morphology, which was comparable with the morphology of unstimulated macrophages (Figure 1A).

The three macrophage subsets showed compared to the reference gene tyrosine 3-monooxygenase/tryptophan 5monooxygenase activation protein, zeta polypeptide (YWHAZ), a high expression of CD68, which is a general marker for macrophages. M1 macrophages had a lower CD68 expression than M2 polarized or unstimulated macrophages (Figure 1B). CD14, a co-receptor for toll-like receptor 4 (TLR4), is involved in LPS recognition and is upregulated by M1 polarized macrophages compared to M2 or unstimulated macrophages (Figure 1B).

Macrophages stimulated for $48 \mathrm{~h}$ with LPS/IFNG showed an upregulation of the inflammatory genes interleukin 1 beta (IL1B), IL6 and CCL2 compared to M2 polarized and unstimulated macrophages (Figure 1C). A similar upregulation of CD40, a protein involved in the activation of antigen presenting cells, was seen after LPS/IFNG stimulation (Figure 1C).

Macrophages stimulated with IL4/IL13 showed an upregulated gene expression of C-type lectin domain family 10, member A (CLEC10A; also known as macrophage galactose $\mathrm{N}$-acetyl-galactosamine specific lectin) and mannose receptor, $\mathrm{C}$ type 1 (MRC1) compared to M1 polarized or unstimulated macrophages. CCL18 tended to be upregulated in IL4/IL13 stimulated macrophages while interleukin 1 receptor, type II (IL1R2), which acts as a decoy receptor for the type I interleukin 1 , showed a higher expression in IL4/IL13 and unstimulated macrophages than M1 polarized macrophages (Figure 1D). M1 macrophages secreted significantly more CCL2 compared to M2 and unstimulated macrophages. M2 and M1 macrophages secreted more CCL18 compared to unstimulated macrophages, but no significant differences in secretion were seen between M1 and M2 (Figure 1E). M1 macrophages secreted more pro-inflammatory cytokines and chemokines compared to M2 and unstimulated macrophages (Table 1). M2 macrophages secreted fibroblast growth factor 2 (FGF2), which was significant different compared to M1 and unstimulated macrophages (Table 1).

Overall, our results indicate that M1 polarized macrophages were pro-inflammatory while M2 polarized macrophages were non-inflammatory and unstimulated macrophages adopted a M2 "intermediate" phenotype.

\section{Morphology of HDFs stimulated with conditioned medium (CM) of M1 polarized, M2 polarized, or unstimulated macrophages}

Dermal fibroblasts were stimulated with CM of M1 polarized, M2 polarized or unstimulated macrophages for $24 \mathrm{~h}, 48 \mathrm{~h}, 72 \mathrm{~h}$ and $144 \mathrm{~h}$. After $24 \mathrm{~h}$ of stimulation, the 


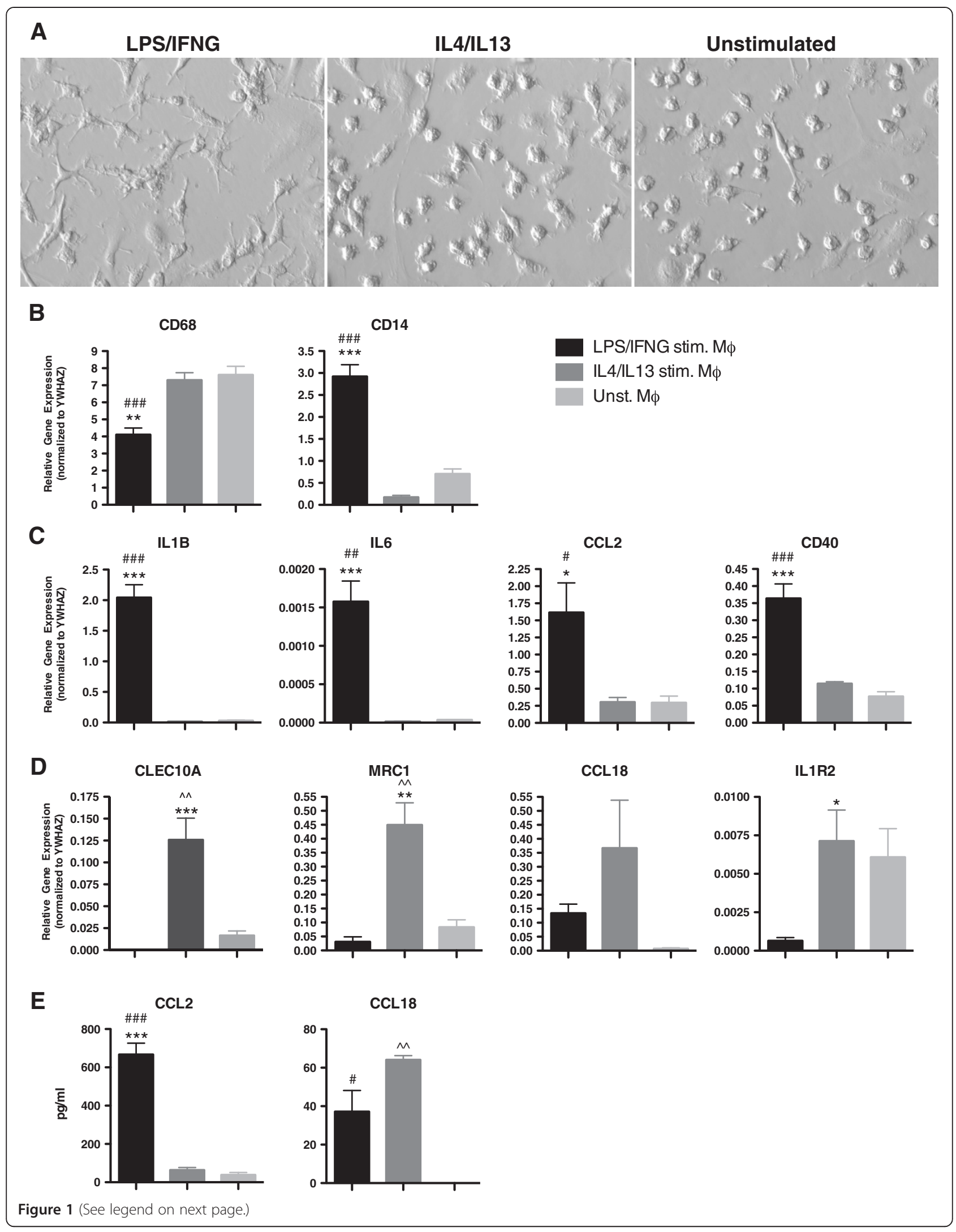


(See figure on previous page.)

Figure 1 Characterization of macrophages after M1 or M2 polarization. After stimulation with LPS/IFNG, M1 macrophages showed a dendritic morphology while IL4/IL13 (M2) stimulated and unstimulated macrophages showed a rounded and/or spindle-shaped morphology (A). The three primary macrophages subsets showed, compared to reference gene YWHAZ, a high expression of CD68. In M1 polarized macrophages the CD68 gene expression is downregulated while the expression of CD14 is upregulated compared to M2 or unstimulated macrophages (B). LPS/IFNG-stimulated (M1) macrophages showed upregulated gene expression of IL1B, IL6, CCL2 and CD40 (C). IL4/IL13-stimulated (M2) macrophages upregulated the gene expression of CLEC10A, MRC1 and tended to upregulate CCL18. IL1R2 showed a high expression in M2 and unstimulated macrophages and was downregulated in M1 polarized macrophages (D). At protein level, more CCL2 was observed in conditioned medium from M1 macrophages. CCL18 protein secretion showed, like CCL2, values that correlated with gene expression (E). ${ }^{*} p<0.05$, Difference between LPS/IFNG and IL4/IL13 stimulated macrophages, ${ }^{* *} p<0.01$, ${ }^{* * *} p<0.001$. \# $p<0.05$, Difference between LPS/IFNG stimulated and unstimulated macrophages, \#\#\#p<0.001. $\wedge p<0.01$, Difference between IL4/IL13 stimulated and unstimulated macrophages. Data were analyzed using one-way ANOVA followed by Tukey's post-test. Gene expression analysis $n=4$, protein secretion $n=3$.

fibroblasts showed a spindle-shaped morphology in all three conditions (Figure 2A, B, C). After $24 \mathrm{~h}$ of stimulation with $\mathrm{CM}$ of M1 macrophages some rounded fibroblasts were seen, which were not present in the fibroblast cultures stimulated with CM of M2 polarized or unstimulated macrophages (Figure 2A). After $48 \mathrm{~h}$ of stimulation, the morphology of the fibroblasts was similar to that of $24 \mathrm{~h}$ of stimulation (data not shown). However, the fibroblast morphology changes in time. CM of M1 macrophages induced a rounded morphology, which was clearly seen after $72 \mathrm{~h}$ (Figure 2D) and 144 h (Figure 2G), while fibroblasts stimulated with CM of M2 macrophages adopted an elongated spindle-shaped cell morphology after $72 \mathrm{~h}$ and $144 \mathrm{~h}$ (Figure 2E, and H). The morphology of fibroblasts stimulated with $\mathrm{CM}$ of unstimulated macrophages had a spindle-shaped morphology after $72 \mathrm{~h}$ and $144 \mathrm{~h}$ (Figure 2F and I) that was similar to $24 \mathrm{~h}$ (Figure 2C). This morphology was also seen by fibroblasts cultured in control medium (data not shown).

CM from M1 macrophages induces a pro-inflammatory HDF HDFs showed, after stimulation with CM of M1 macrophages, a $>10$-fold increase in the expression of the pro- inflammatory gene CCL2 compared to fibroblasts stimulated with $\mathrm{CM}$ of $\mathrm{M} 2$ or unstimulated macrophages at all time points (Figure 3A). The expression of the proinflammatory genes IL6 and CCL7 was $>100$-fold upregulated at all time points by fibroblasts stimulated with $\mathrm{CM}$ of $\mathrm{M} 1$ macrophages compared to fibroblasts stimulated with $\mathrm{CM}$ of $\mathrm{M} 2$ or unstimulated macrophages (Figure 3A).

Secretion of the cytokines CCL2, IL6 and chemokine CCL7 by dermal fibroblasts was determined after $24 \mathrm{~h}$ and $48 \mathrm{~h}$ of stimulation. Fibroblasts stimulated with CM of M1 macrophages secreted significantly more CCL2 and IL6 compared to fibroblasts stimulated with CM of M2 macrophages or unstimulated macrophages after $24 \mathrm{~h}$ and $48 \mathrm{~h}$ (Figure 3B). Secretion of CCL7 by M1 CM stimulated fibroblasts was higher after $24 \mathrm{~h}$ and becomes significant after $48 \mathrm{~h}$ of stimulation compared to fibroblasts stimulated with M2 or unstimulated macrophages CM (Figure 3B). These results are in accordance with the gene expression patterns of the stimulated fibroblasts.

The results indicate that M1 macrophages induce, by means of paracrine signaling, a pro-inflammatory dermal fibroblast.

Table 1 Overview secreted cytokines, chemokines and growth factors by different polarized macrophages

\begin{tabular}{|c|c|c|c|c|c|c|}
\hline \multirow[b]{2}{*}{ Protein symbol } & \multicolumn{3}{|c|}{ Secreted factors by macrophages (pg/ml) } & \multicolumn{3}{|c|}{ Ratio } \\
\hline & M1 & M2 & Unst. & M1:M2 & M1:Unst. & M2:Unst \\
\hline $\mathrm{CCL} 2$ & $743 \pm 123$ & 0 & 0 & 743 & 743 & 1 \\
\hline CCL3 & $45 \pm 28$ & 0 & 0 & 45 & 45 & 1 \\
\hline CCL4 & $192 \pm 59$ & 0 & 0 & 192 & 192 & 1 \\
\hline CCL5 & $26 \pm 9$ & 0 & 0 & 26 & 26 & 1 \\
\hline CCL18 & $37 \pm 19$ & $64 \pm 4$ & 0 & -2 & 37 & 64 \\
\hline CXCL9 & $183 \pm 80$ & 0 & 0 & 183 & 183 & 1 \\
\hline CXCL10 & $370 \pm 83$ & $7,4 \pm 1,9$ & $7,4 \pm 1,2$ & 50 & 50 & 1 \\
\hline FGF2 & $1,6 \pm 3,2$ & $10 \pm 4$ & 0 & -6 & 1 & 10 \\
\hline IL6 & $31 \pm 7$ & 0 & 0 & 31 & 31 & 1 \\
\hline IL8 & $1171 \pm 388$ & $52 \pm 11$ & $63 \pm 19$ & 23 & 19 & 1 \\
\hline IL12p40/p70 & $84 \pm 30$ & 0 & 0 & 84 & 84 & 1 \\
\hline IL15 & $40 \pm 11$ & 0 & 0 & 40 & 40 & 1 \\
\hline
\end{tabular}



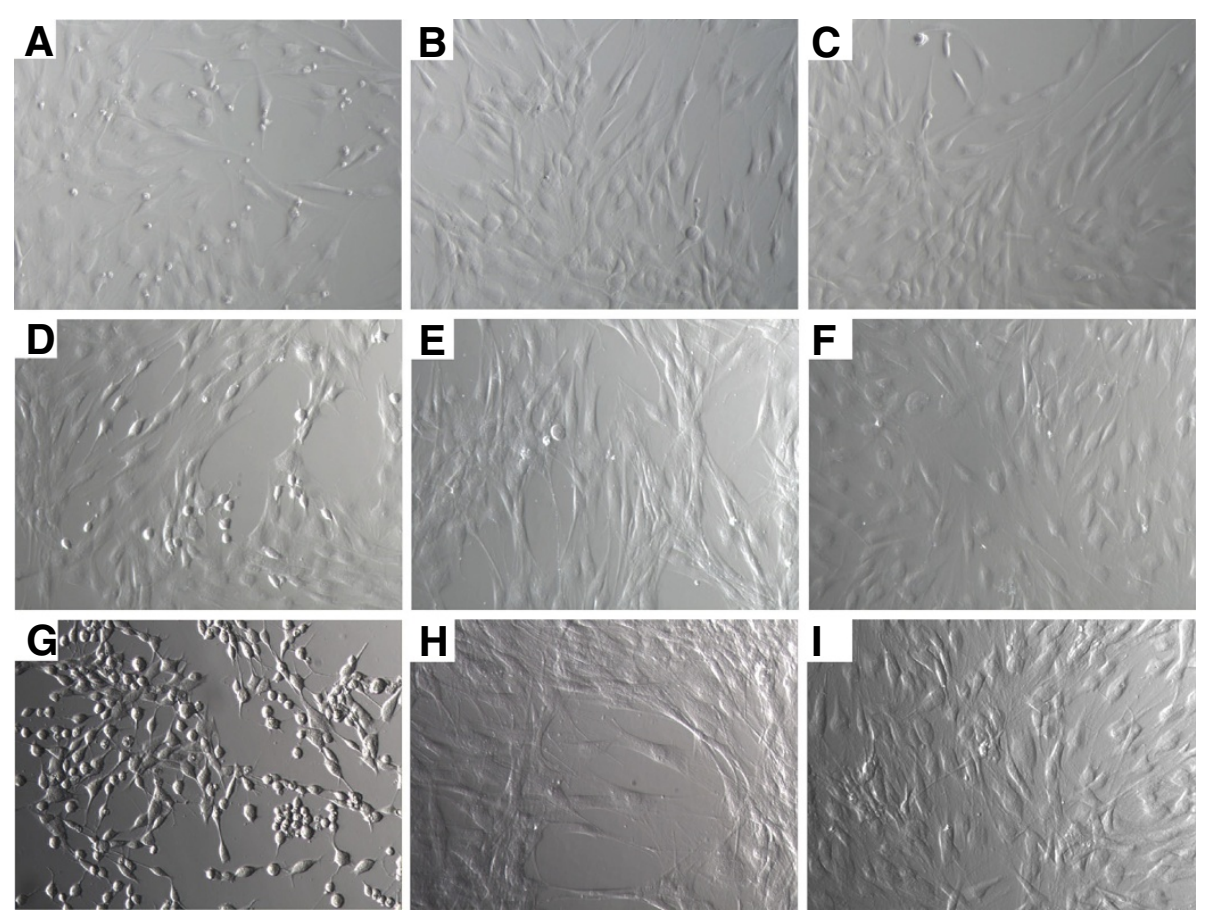

Figure 2 Morphology of HDFs stimulated with CM of M1 polarized, M2 polarized, or unstimulated macrophages. HDFs stimulated with CM of M1 polarized macrophages; $24 \mathrm{~h}(\mathbf{A}), 72 \mathrm{~h}(\mathbf{D})$, and $144 \mathrm{~h}(\mathbf{G})$. After $24 \mathrm{~h}$, most of the fibroblasts showed a spindle-shaped morphology although some rounded fibroblasts were seen. After $72 \mathrm{~h}$, the fibroblasts adopted a rounded morphology that was most prominent after $144 \mathrm{~h}$. HDFs stimulated with CM of M2 polarized macrophages; $24 \mathrm{~h}(\mathbf{B}), 72 \mathrm{~h}(\mathbf{E})$ and $144 \mathrm{~h}(\mathbf{H})$. After $24 \mathrm{~h}$ the cells showed a spindle-like morphology, which was changed into an elongated spindle-like morphology after $72 \mathrm{~h}$. HDFs stimulated with CM from unstimulated macrophages $24 \mathrm{~h}$

$(\mathbf{C}), 72 \mathrm{~h}(\mathbf{F})$, and $144 \mathrm{~h}$ (I). The fibroblasts showed a spindle-like morphology after $24 \mathrm{~h}$, which was not changed in time.

\section{CM from M1 macrophages induces the expression of ECM degrading enzymes by HDFs}

Stimulation of dermal fibroblasts with CM of M1 macrophages already showed an upregulated gene expression of MMP1, MMP2, MMP3 and MMP14 compared to the other conditions after $24 \mathrm{~h}$ (Figure 4A). These MMP gene expression profiles were consistently upregulated over time, except for MMP2 and MMP14 after $144 \mathrm{~h}$. Tissue inhibitor of metalloproteinases -1 (TIMP1) was also upregulated ( $2-3$ fold) in fibroblasts stimulated with CM of M1 macrophages, but the total MMP gene expression levels were much higher upregulated: MMP1 and MMP3 were $>10$ and $>100$ fold upregulated, respectively (Figure 4A). On protein level, the secretion of MMP1, MMP2 and MMP3 were upregulated by fibroblasts after stimulation with CM of M1 macrophages in the same order of magnitude as observed by the respective expression data (Figure 4B). Indeed, the secreted MMPs showed a higher net proteolytic activity compared to medium derived from fibroblasts stimulated with $\mathrm{CM}$ of $\mathrm{M} 2$ or unstimulated macrophages (Figure 4C).

The results indicate that fibroblasts subjected to factors produced by M1 macrophages show enhanced ECM degradation properties.
CM of M1 polarized, M2 polarized or unstimulated macrophages does not induce myofibroblast differentiation of HDFs

Alpha-actin-2 (ACTA2; also known as alpha Smooth Muscle Actin), a marker for myofibroblast formation, is upregulated at gene expression level by fibroblasts stimulated with $\mathrm{CM}$ of unstimulated macrophages compared to $\mathrm{CM}$ of M1 stimulated macrophages after $48 \mathrm{~h}, 72 \mathrm{~h}$ and $144 \mathrm{~h}$. Fibroblasts stimulated with CM of M2 macrophages showed an upregulation of ACTA2 compared to fibroblasts stimulated with $\mathrm{CM}$ of $\mathrm{M} 1$ macrophages after $144 \mathrm{~h}$ (Figure 5A). No differences were observed in transgelin (TAGLN) (smooth muscle protein 22-alpha) gene expression, a calponin that is mainly expressed by smooth muscle cells and myofibroblasts (Figure 5A).

On protein level no ACTA2 was seen in fibroblasts after $144 \mathrm{~h}$ of stimulation with the three different $\mathrm{CM}$. This was in contrast to TGFB1 stimulated fibroblasts (myofibroblasts), which showed ACTA2 protein expression after $144 \mathrm{~h}$ (Figure 5B). TGFB1 stimulated fibroblasts showed a higher contractile force compared with fibroblasts stimulated with CM of different macrophages in a collagen gel contraction assay (Figure 5C). Fibroblasts stimulated with $\mathrm{CM}$ of M1 macrophages contract the collagen gel slightly more than fibroblasts stimulated 


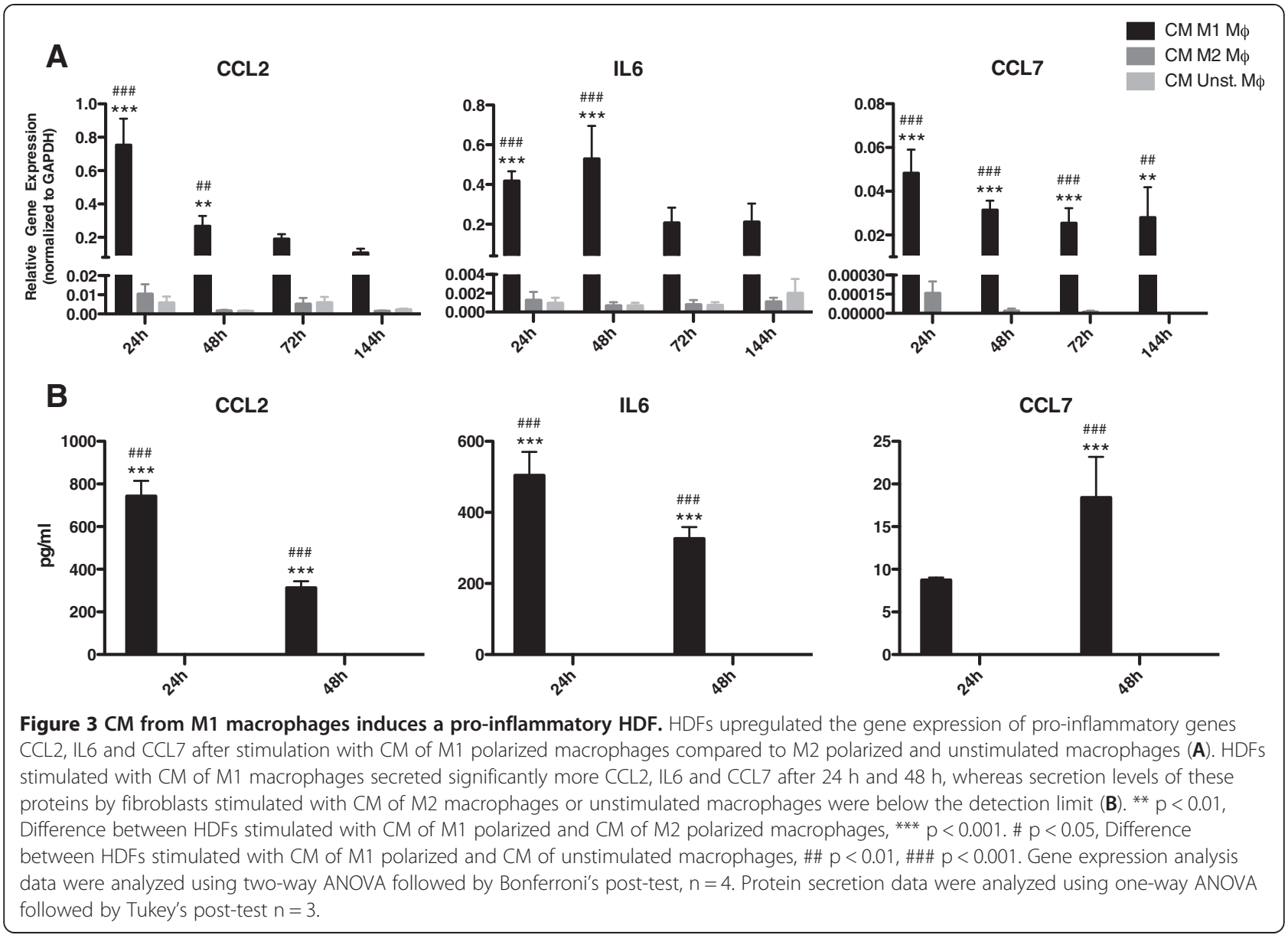

with $\mathrm{CM}$ of $\mathrm{M} 2$ and unstimulated fibroblasts. It is reported by Zhu et al. that active MMPs increases collagen gel contraction $[35,36]$. It is likely that the secretion of active MMPs by fibroblasts stimulated with M1 CM causes the observed gel contraction.

Together, these results indicate that CM from M1, M2 or unstimulated macrophages did not result in the differentiation of fibroblasts into myofibroblasts.

\section{Proliferation of HDFs is induced by CM of M2 macrophages}

After $72 \mathrm{~h}$, fibroblast cell numbers were similar in all conditions, but increased exclusively after stimulation with CM of M2 macrophages after 144 h (Figure 6A). Nuclear protein Ki-67 (MKI67), a cellular marker for proliferation, showed the same amount of positive nuclei at $24 \mathrm{~h}$ in all conditions. This indicates that a comparable proliferation rate occurs at $24 \mathrm{~h}$ (Figure 6B). At $144 \mathrm{~h}$, more MKI67 positive nuclei were seen when fibroblasts were stimulated with $\mathrm{CM}$ of M2 macrophages compared to CM from M1 or unstimulated macrophages, although in all three conditions positive nuclei were seen (Figure 6B and $\mathrm{C}$ ).
The results indicate that CM from M2 macrophages induced proliferation of fibroblasts.

\section{Influence of CM of M1 polarized, M2 polarized or unstimulated macrophages on extracellular matrix deposition by HDFs}

ECM deposition by fibroblasts is an important process in wound healing and fibrosis. Two major collagens produced in these processes are collagen type I (COL1A1) and collagen type III (COL3A1). COL1A1 gene expression in fibroblasts was reduced after stimulation with $\mathrm{CM}$ of M1 macrophages compared to CM of M2 and unstimulated macrophages after $144 \mathrm{~h}$ (Figure 7A). CM of M1 macrophages reduced COL3A1 gene expression in fibroblasts compared to CM of M2 macrophages at $144 \mathrm{~h}$ (Figure 7A). No difference in COL1A1 and COL3A1 gene expression was seen in fibroblasts stimulated with $\mathrm{CM}$ of M2 or unstimulated macrophages compared to fibroblasts cultured in control medium (data not shown).

After $72 \mathrm{~h}$, no difference in collagen type I deposition was seen after the different stimulations. However, less collagen type I protein deposition was seen by fibroblasts stimulated with $\mathrm{CM}$ of $\mathrm{M} 1$ macrophages compared to 


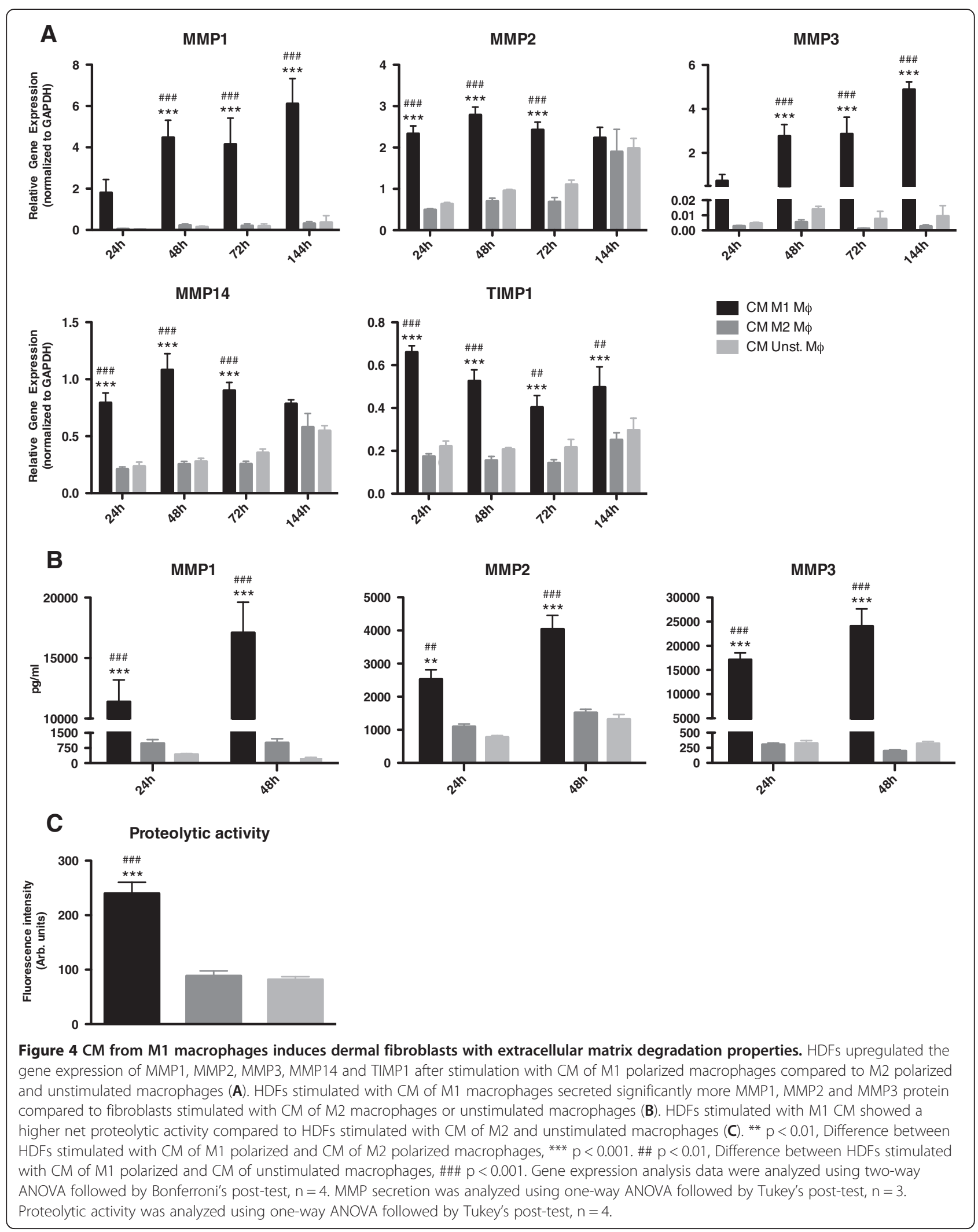



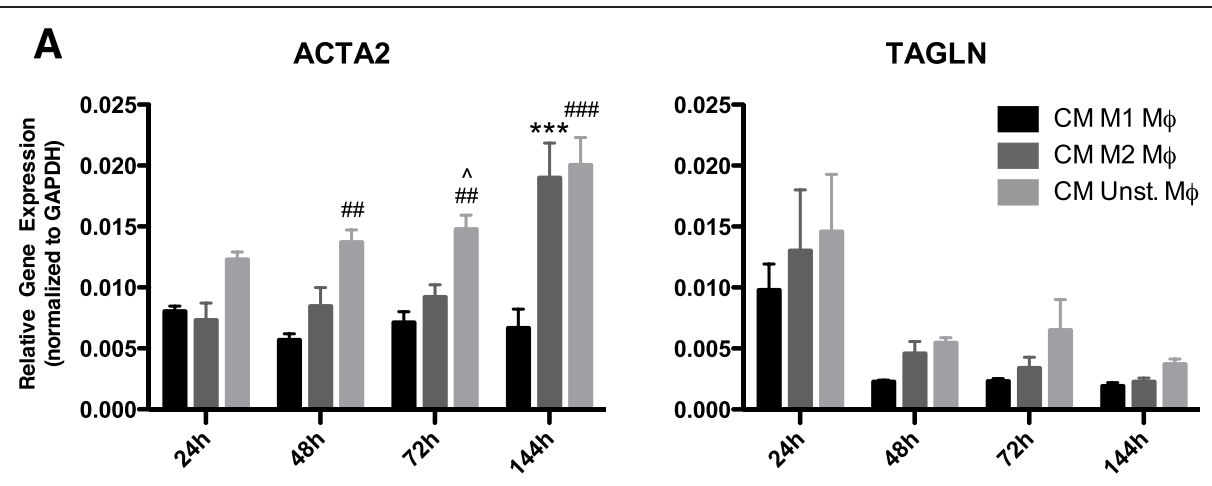

B

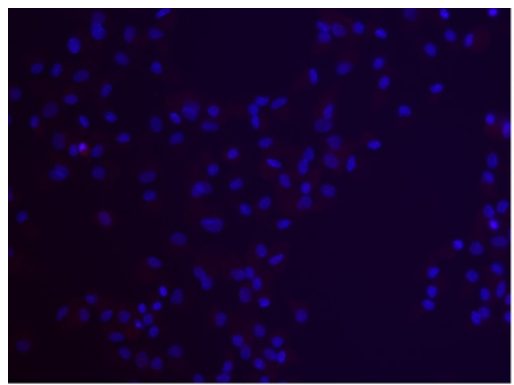

CM M1 M $\phi$

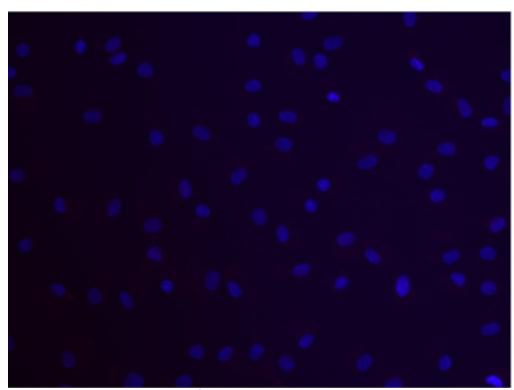

CM Unst. M $\phi$

C

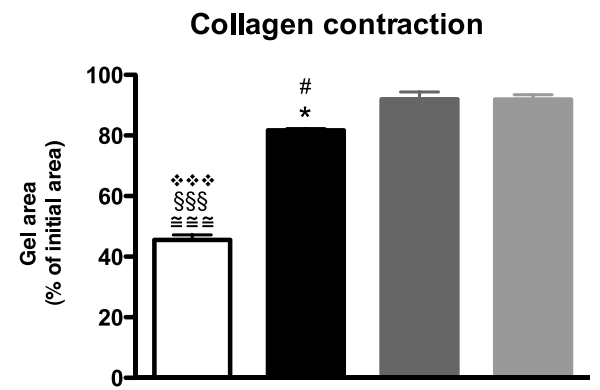

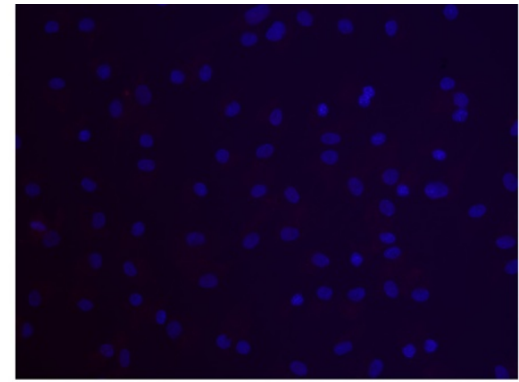

CM M2 M $\phi$

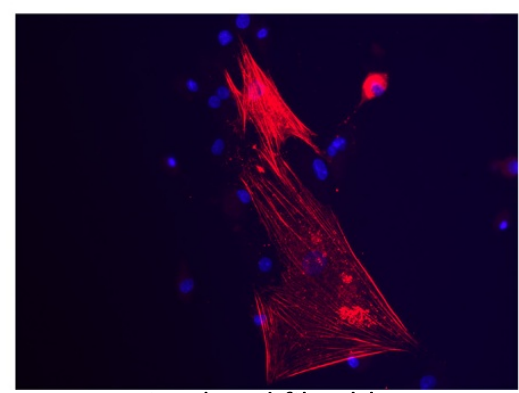

TGFB1 stimulated fibroblasts

TGFB1 stimulated

$\mathrm{CM} \mathrm{M} 1 \mathrm{M} \phi$

$\mathrm{CM} \mathrm{M} 2 \mathrm{M} \phi$

CM Unst. M $\phi$

Figure 5 (See legend on next page.) 
(See figure on previous page.)

Figure 5 CM of M1 polarized, M2 polarized or unstimulated macrophages do not induce myofibroblast differentiation of HDFs. HDFs stimulated with CM of unstimulated macrophages showed, compared to fibroblasts stimulated with CM of M1 polarized macrophages, an upregulated gene expression of ACTA2 after $48 \mathrm{~h}, 72 \mathrm{~h}$ and $144 \mathrm{~h}$. HDFs stimulated with CM of M2 polarized macrophages showed a higher gene expression of ACTA2 compared to HDFs stimulated with CM of M1 macrophages after $144 \mathrm{~h}(\mathbf{A})$. No differences were observed in TAGLN gene expression between the three conditions in all time points $(\mathbf{A})$. No differences in ACTA2 protein expression were seen between the three conditions after $144 \mathrm{~h}$. TGFB1 stimulated fibroblasts were used as positive control (B). Fibroblasts stimulated with CM of M1 macrophages contract the collagen 10\% more than fibroblasts stimulated with CM of M2 and unstimulated fibroblasts. Fibroblasts stimulated with TGFB1 contract the collagen 50\% more compared to the other stimulations $(\mathbf{C}) .{ }^{*} p<0.05$, Difference between HDFs stimulated with CM of M1 polarized and CM of M2 polarized macrophages, ${ }^{* *} p<0.001$. \# $p<0.05$, Difference between HDFs stimulated with CM of M1 polarized and CM of unstimulated macrophages, \#\# $p<0.01$, \#\#\# $p<0.001 . \wedge p<0.05$, Difference between HDFs stimulated with CM of M2 polarized and CM of unstimulated macrophages. $\cong \cong x<0.001$, Difference between HDFs stimulated with TGFB1 and CM of M1 polarized macrophages. $\S \S \S p<0.001$, Difference between HDFs stimulated with TGFB1 and CM of M2 polarized macrophages. $* p<0.001$, Difference between HDFs stimulated with TGFB1 and CM of unstimulated polarized macrophages. Gene expression analysis data were analyzed using two-way ANOVA followed by Bonferroni's post-test, $n=4$. ACTA2 protein expression was shown in red and nuclei in blue (DAPI), original magnification 200x. Collagen gel contraction analysis data were analyzed using one-way ANOVA followed by Tukey's post-test, $\mathrm{n}=3$.

the other conditions after $144 \mathrm{~h}$ (Figure $7 \mathrm{~B})$. These results are in accordance with the gene expression patterns of the stimulated fibroblasts.

The results indicate that $\mathrm{CM}$ of $\mathrm{M} 1$ macrophages reduce ECM deposition by fibroblasts.
HDFs stimulated with CM of M1 macrophages followed by stimulation with CM of M2 macrophages or non-CM (switch) In wound healing, the inflammatory phase is normally followed by the healing phase. In both phases macrophages and fibroblasts play an important role. In vitro, it

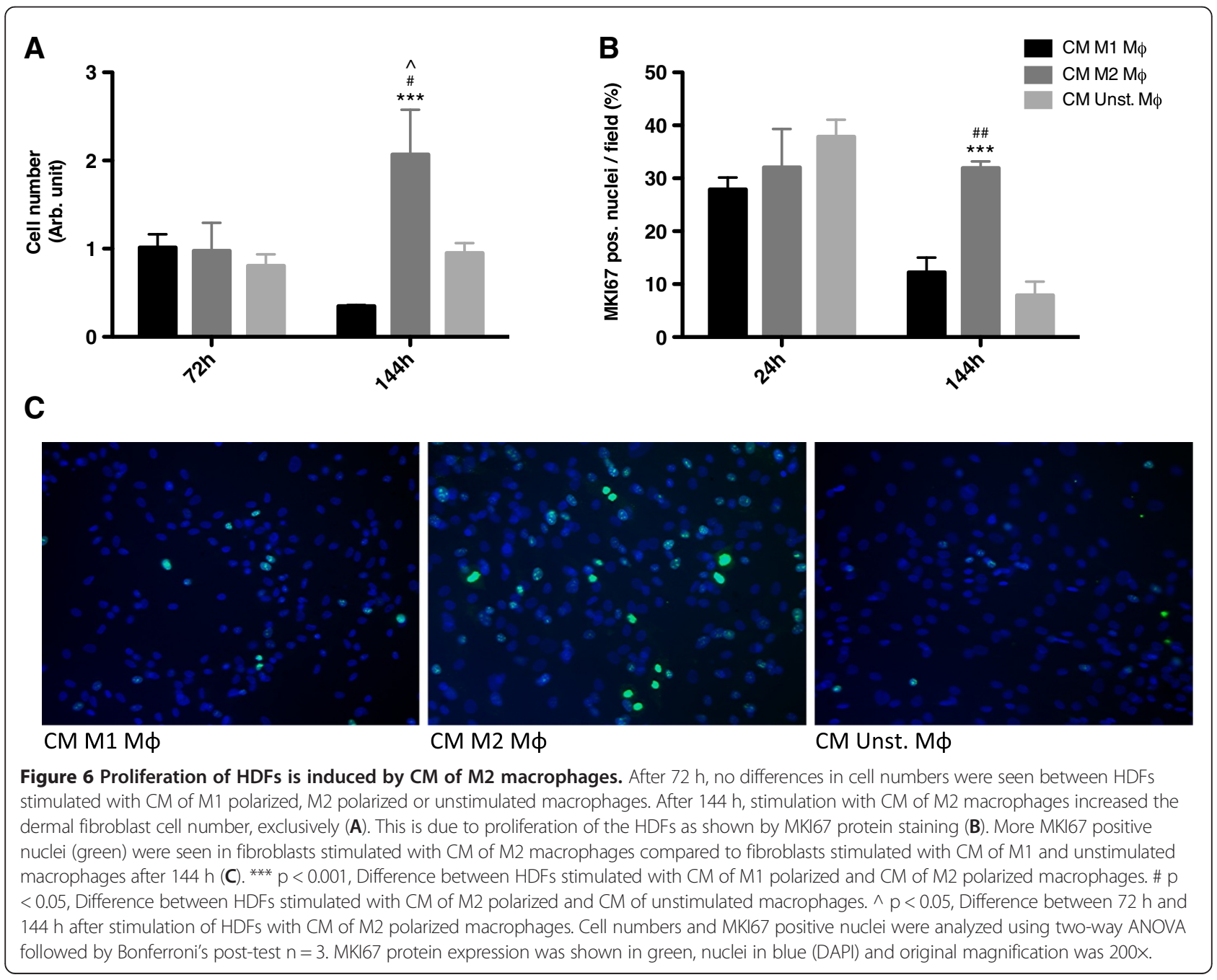




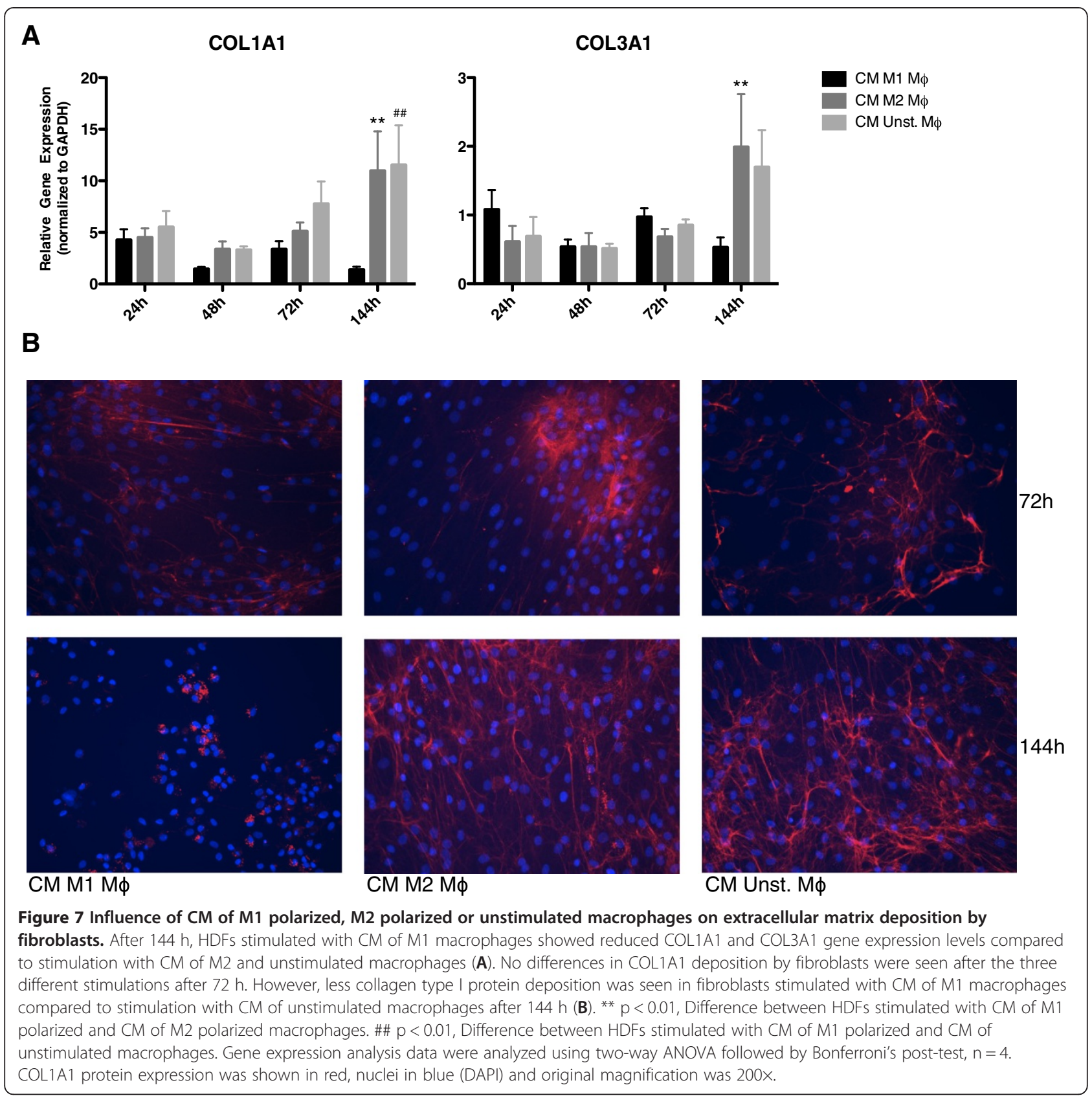

is shown that macrophages can be re-polarized from M1 to M2 and vice versa [26,27]. In vivo, there are indications that re-polarization of macrophages also occurs [28,29]. Therefore we investigated the influence of CM of M1 macrophages on fibroblasts followed by stimulation with CM of M2 macrophages or non-CM at $72 \mathrm{~h}$ (24 h CM M1 followed by $48 \mathrm{~h}$ CM M2 or non-CM) and $144 \mathrm{~h} \mathrm{(48} \mathrm{h}$ CM M1 followed by 96 h CM M2 or non-CM).

As shown in Figure 3, fibroblasts became proinflammatory after stimulation with $\mathrm{CM}$ of $\mathrm{M} 1$ macrophages. Figure 8A shows that if this stimulation is followed by $\mathrm{CM}$ of M2 macrophages or non-CM, the fibroblasts completely downregulated the gene expression of CCL2 and IL6 both after $72 \mathrm{~h}$ and $144 \mathrm{~h}$. The gene expression level of CCL2 and IL6 was similar to fibroblasts stimulated with only CM of M2 macrophages at both time points.

As shown in Figure 4, expression levels of MMP1, MMP2 and MMP14 were upregulated after stimulation of CM from M1 macrophages. Fibroblasts which were stimulated with $\mathrm{CM}$ of $\mathrm{M} 1$ followed by $\mathrm{CM}$ of M2 macrophages or non-CM, showed a downregulation in the gene expression of MMP1 after $72 \mathrm{~h}$ and $144 \mathrm{~h}$ (Figure 8B). MMP2 expression by fibroblasts after the CM switch 


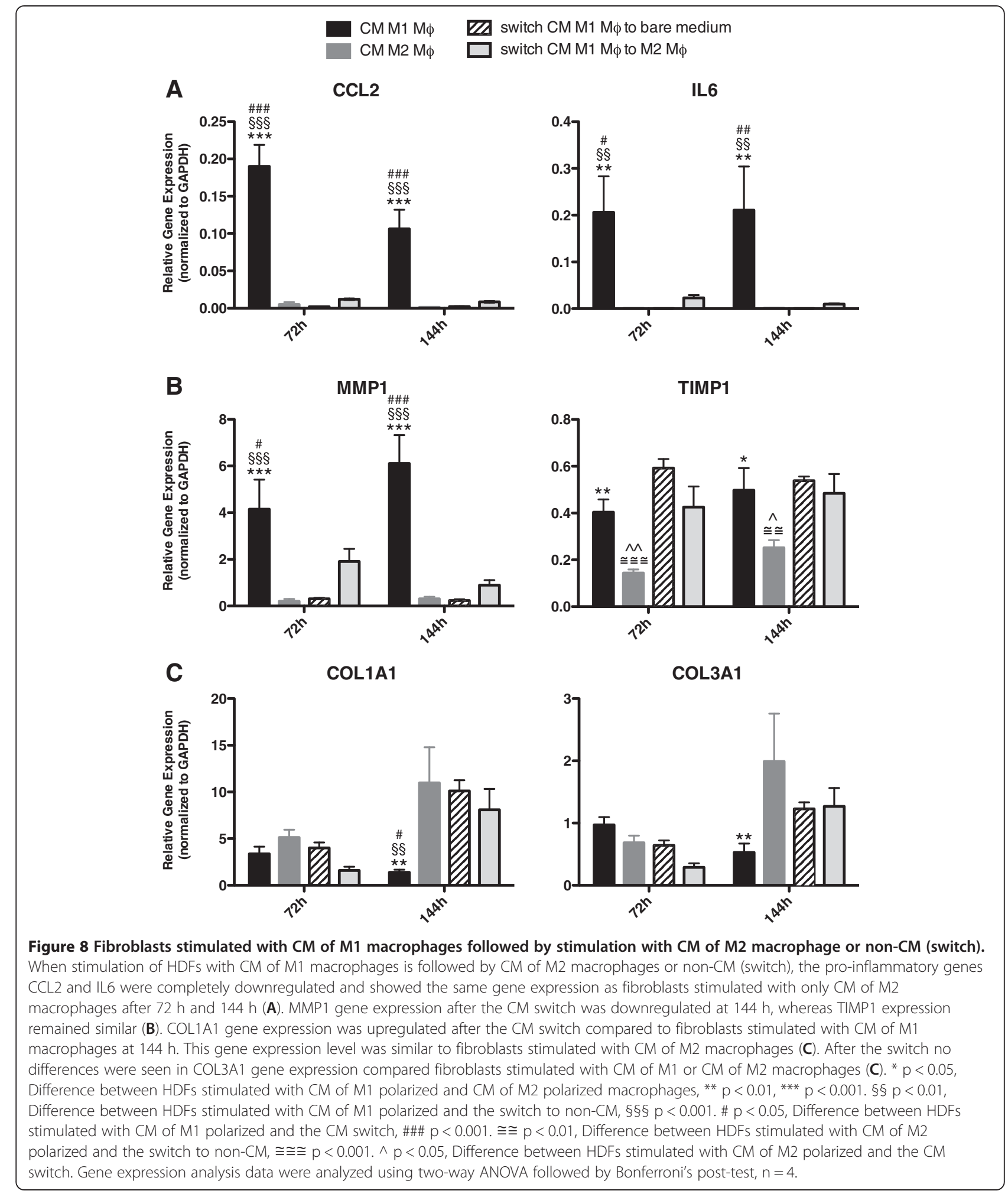

showed a slight decrease after $72 \mathrm{~h}$. After $144 \mathrm{~h}$, no differences in MMP2 expression levels were seen between fibroblasts stimulated with CM of M1 or M2 macrophages nor the switch (data not shown). MMP14 gene expression was downregulated in fibroblasts that were stimulated with $\mathrm{CM}$ of M1 followed by $\mathrm{CM}$ of M2 macrophages or non-CM compared to stimulation with $\mathrm{CM}$ of M1 macrophages after $72 \mathrm{~h}$. Similar to the gene expression of MMP2, no differences in MMP14 expression were seen between the conditions after $144 \mathrm{~h}$ (data not shown). As 
shown in Figure 4A, TIMP1 was upregulated in fibroblasts after stimulation with $\mathrm{CM}$ of M1 macrophages. Fibroblasts, stimulated with $\mathrm{CM}$ of M1 followed by CM of M2 macrophages or non-CM, showed a TIMP1 gene expression that remained high at $72 \mathrm{~h}$ and $144 \mathrm{~h}$, which was significantly different compared to fibroblasts stimulated with $\mathrm{CM}$ of $\mathrm{M} 2$ macrophages alone (Figure $8 \mathrm{~B}$ ), indicating that $\mathrm{CM}$ of $\mathrm{M} 2$ macrophages nor non-CM was not able to suppress the induction of TIMP expression by CM of M1 macrophages.

ACTA2 gene expression was similar between fibroblasts stimulated with CM of M1 or M2 macrophages or the switch after $72 \mathrm{~h}$. After $144 \mathrm{~h}$ fibroblasts stimulated with $\mathrm{CM}$ of M2 macrophages or the switch showed higher expression of ACTA2 compared to fibroblasts stimulated with only CM of M1 macrophages (data not shown). No differences were seen in TAGLN gene expression between the three conditions (data not shown).

COL1A1 gene expression was upregulated after the switch of CM compared to fibroblasts stimulated with M1 macrophages CM at $144 \mathrm{~h}$ (Figure $8 \mathrm{C}$ ). This gene expression was similar to fibroblasts stimulated with $\mathrm{CM}$ of M2 macrophages after $144 \mathrm{~h}$. No differences in COL3A1 gene expression were seen after the switch compared to fibroblasts stimulated with M1 or M2 CM in time.

The results indicate that the effects of factors produced by M1 macrophages on HDFs diminish once HFDs are not exposed to these factors anymore (i.e. if HDFs are exposed to M2-CM or non-CM).

\section{Discussion}

Macrophages play important roles in wound repair processes. Macrophages are phenotypically highly plastic, and their polarization state depends on the microenvironment present in the wounded area. The M1 and M2 polarization states are opposite activation states of a continuum. Protocols to induce M1 and M2 macrophages in vitro are widely used, but it should be realized that the macrophage phenotype in wounds likely exhibit a more complex phenotype in (certain stages of) wound healing [37-39]. Nevertheless, since M1 and M2 macrophages are well-defined extremes, they offer interesting opportunities to study processes encountered during wound healing.

In this study we investigated the influence of secreted factors (conditioned medium) of M1 or M2 macrophages on dermal fibroblasts. Simultaneously, the influence of secreted factors of M1 macrophages followed by stimulation with secreted factors of M2 macrophages was investigated. In addition, we used conditioned medium from unstimulated macrophages. These unstimulated macrophages have a "M2-like" phenotype, which is probably caused by stimulating monocytes with macrophage colony-stimulating factor (M-CSF), a step that is necessary to induce differentiation of monocytes towards macrophages [40,41]. Despite this, the obtained macrophages changed their polarization status quickly when stimulated with LPS/ IFNG or IL4/IL13 towards M1 or M2 macrophages, respectively. Secreted factors of these three types of macrophages influenced fibroblasts morphology and phenotype considerably.

In general, macrophages that invade the tissue in the inflammatory phase of wound healing adopt a M1 phenotype. In our model, the secreted factors from M1 macrophages influences the properties of dermal fibroblasts already within $24 \mathrm{~h}$, changing the phenotype into a proinflammatory state. This indicates that fibroblasts, under the direction of paracrine signals of M1 macrophages, contribute to a pro-inflammatory environment by secreting cytokines and chemokines (such as CCL2, CCL7 and IL6) in the inflammatory phase of wound healing. This is in accordance with data shown by Holt et al. [34]. These authors showed, in an in vitro model with murine primary cells and cell lines, that fibroblasts produce proinflammatory cytokines and chemokines after stimulation with conditioned medium of LPS-stimulated macrophages and in a co-culture system with direct cell-cell contact. Other studies [30,32,33] showed that after direct contact between macrophages and fibroblasts, without paying attention to the M1/M2 status of macrophages, fibroblasts upregulated the inflammatory proteins CCL2 and CCL3, which is in accordance to our results from fibroblasts stimulated with secreted factors from M1 macrophages.

MMPs are capable of regulating chemokine activity and ECM degradation in tissue repair $[42,43]$. MMPs are important as they support cellular influxes, but an excess of MMPs will damage the tissue architecture and a high TIMP/MMP ratio is often seen in non-healing tissues. In the inflammation phase of tissue repair MMPs are upregulated and the moment fibroblasts deposit new ECM the MMPs levels decline. In our model we showed that different MMPs (MMP1, MMP2, MMP3 and MMP14) were highly upregulated in fibroblasts that were exposed to paracrine factors derived from M1 macrophages. Because of the secreted MMPs and the proinflammatory state of fibroblasts after M1 stimulation, it is likely that in vivo the fibroblasts are able to prolong the inflammation state in wound healing by itself or by attracting more pro-inflammatory cells.

Fibroblasts exposed to conditioned medium from M2 macrophages showed little response. Only a slight increase was seen in the expression of ACTA2, but this did not resulted in myofibroblast formation. Furthermore, an increase in cell proliferation was seen, which was in accordance with previous findings [22,23,31,44].

In wound repair it is thought that M2 macrophages are responsible for reversing the inflammatory response, 
thereby initiating the healing process. Interestingly, in this study we show that fibroblasts with an inflammatory phenotype (initiated by stimulation with secreted factors of M1 macrophages) can be reversed to an antiinflammatory phenotype with secreted factors of M2 macrophages or non-CM. In these fibroblasts, the previously upregulated pro-inflammatory cytokines, chemokines, and MMPs were completely downregulated after stimulation with paracrine signals from M2 macrophages or non-CM. Thus, although paracrine factors of M2 macrophages have relatively little effect on unstimulated fibroblasts, they can have a major effect on fibroblasts with an inflammatory phenotype.

\section{Conclusions}

In summary, we have shown that secreted factors from M1 macrophages gives rise to fibroblasts with a proinflammatory and ECM-degrading profile, while M2 macrophages induce fibroblast proliferation. The proinflammatory and ECM-degrading fibroblast can be reversed completely by secreted factors from M2 macrophages or non-CM. Therefore, not only macrophages, but also fibroblasts show a high dynamic plasticity in wound healing / tissue repair processes, a plasticity that seems to be regulated by the micro-environment.

\section{Material and methods}

\section{Isolation of $\mathrm{CD} 14^{+}$cells}

Human peripheral blood mononuclear cells (PBMCs) from healthy donors were isolated from buffy coats (Sanquin, Groningen, the Netherlands) by densitygradient centrifugation using Lymphoprep (Axis-Shield, Oslo, Norway) according to the manufacturer's protocol. Briefly, blood was diluted three times with isolation buffer ( $\mathrm{pH}$ 7.4) consisting of phosphate buffered saline (PBS) with $0.5 \%$ fetal bovine serum (FBS; Life Technologies Europe BV, Bleiswijk, the Netherlands) and 2 mM EDTA (Merck, Darmstadt, Germany). This mixture (30 ml) was layered over $20 \mathrm{ml}$ of Lymphoprep and centrifuged at $800 \times \mathrm{g}$ for $30 \mathrm{~min}$. Residual erythrocytes were lysed on ice $(10 \mathrm{~min})$ in $155 \mathrm{mM} \mathrm{NH}_{4} \mathrm{Cl}, 10 \mathrm{mM} \mathrm{KHCO} 3,0.1 \mathrm{mM}$ EDTA ( $\mathrm{pH}$ 7.4) and the suspension was centrifuged at $300 \times \mathrm{g}$ at $4^{\circ} \mathrm{C}$ for $10 \mathrm{~min}$ after which the supernatant was discarded and the pellet gently resuspended in isolation buffer. PBMCs were counted using a Coulter Counter (Beckman Coulter, Inc. Brea, USA).

CD $14^{+}$cells were isolated by immunomagnetic bead separation using CD14 Microbeads (Miltenyi Biotec B.V., Leiden, the Netherlands). Briefly, $1 \times 10^{7}$ PBMCs were labeled with $20 \mu \mathrm{l}$ CD14 Microbeads and incubated on ice in $80 \mu \mathrm{l}$ isolation buffer for $30 \mathrm{~min}$. Cells were washed with isolation buffer and the suspension was centrifuged at $300 \times \mathrm{g}$ at $4^{\circ} \mathrm{C}$ for $10 \mathrm{~min}$. The pellet was resuspended in degassed isolation buffer and the CD14 ${ }^{+}$cells were sep- arated with an LS column (Miltenyi Biotec B.V., Leiden, the Netherlands) placed on a column adapter in a strong magnetic field. CD $14^{+}$cells bind to the column and after carefully washing with degassed isolation buffer and removal of the LS column from the magnet the CD $14^{+}$cells were flushed out from the column using a plunger. The $\mathrm{CD}_{14}{ }^{+}$cells were counted with a Coulter Counter and after centrifugation at $300 \times \mathrm{g}$ for $10 \mathrm{~min}$ at $4^{\circ} \mathrm{C}$ gently resuspended in culture medium, consisting of X-VIVO-10 medium (Lonza, Basel, Switzerland) supplemented with 2 mM l-glutamine (Sigma-Aldrich, St. Louis, USA), 1\% penicillin/streptomycin (Sigma-Aldrich, St. Louis, USA) and $10 \mathrm{ng} / \mathrm{ml}$ recombinant human M-CSF (R\&D Systems, Minneapolis, USA).

\section{Macrophage cell culture, polarization with M1 or M2 stimuli and collection of conditioned media}

Immediately after isolation and counting, the cell suspension was plated with a density of 100,000 cells/ $\mathrm{cm}^{2}$ onto tissue culture polystyrene plates (TCPS; Corning Incorporated, NY, USA). Cells were cultured at $37^{\circ} \mathrm{C}$ under $5 \% \mathrm{CO}_{2}$. Cells were refed at day 3 and nonattached cells were removed from culture at day 6 .

At day 6, the adherent cells (macrophages) were washed and stimulated in culture medium (but without M-CSF), with either (1) $1 \mu \mathrm{g} / \mathrm{ml}$ LPS (Sigma-Aldrich, St. Louis, USA) + 10 ng/ml IFNG (PeproTech, Rocky Hill, USA) (classical stimuli), (2) $2 \mathrm{ng} / \mathrm{ml} \mathrm{IL4} \mathrm{+} 2 \mathrm{ng} / \mathrm{ml}$ IL13 (both R\&D, Minneapolis, USA) (alternative stimuli), or (3) no stimulation (control) at $37^{\circ} \mathrm{C}$ for $48 \mathrm{~h}$. The polarization state of the macrophages was determined by quantitative RT-PCR (qRT-PCR). The cells were subsequently washed and cultured in X-VIVO-10 medium for $4 \mathrm{~h}$ (conditioned medium). After $4 \mathrm{~h}$ the CM from (1) M1 macrophages, (2) M2 macrophages and (3) unstimulated macrophages was collected and stored for further analyses at $-20^{\circ} \mathrm{C}$. The $\mathrm{CM}$ of the different conditions were used for stimulation of HDFs, the determination of CCL2 and CCL18 levels by means of enzyme-linked immunosorbent assays (ELISA) and the determination of cytokines with a multiplex bead immunoassay.

\section{HDF cell culture and stimulation with CM of M1, M2 and unstimulated macrophages}

Primary HDFs (\#2320, ScienCell, Carlsbad, USA) were seeded onto TCPS overnight with a density of 15,000 cells/ $\mathrm{cm}^{2}$ in X-VIVO-10 medium containing $2 \mathrm{mM}$ l-glutamine, $1 \%$ penicillin/streptomycin and $50 \mu \mathrm{g} / \mathrm{ml} \mathrm{l-ascorbic} \mathrm{acid} \mathrm{2-}$ phosphate sesquimagnesium salt hydrate (Sigma-Aldrich, St. Louis, USA). The next day the X-VIVO medium was replaced by $\mathrm{CM}$ derived of $\mathrm{M} 1, \mathrm{M} 2$ or unstimulated macrophages, which was supplemented with l-ascorbic acid 2-phosphate sesquimagnesium salt hydrate. Passage 5 or 6 of HDFs were used for stimulations with CM from 
macrophages. The $\mathrm{CM}$ was refreshed every day and the stimulated HDFs were characterized at $24 \mathrm{~h}, 48 \mathrm{~h}, 72 \mathrm{~h}$ and $144 \mathrm{~h}$ by morphology, qRT-PCR and after $24 \mathrm{~h}, 72 \mathrm{~h}$ and $144 \mathrm{~h}$ by immunofluorescent stainings. The deposition of the extracellular matrix protein collagen type I was determined at $72 \mathrm{~h}$ and $144 \mathrm{~h}$. After $24 \mathrm{~h}$ and $48 \mathrm{~h}, \mathrm{CM}$ of stimulated HDFs was collected and stored for further analysis at $-20^{\circ} \mathrm{C}$. Prior to collection of the $\mathrm{CM}$, the stimulated HDFs were washed and cultured in X-VIVO-10 medium for $4 \mathrm{~h}$. CCL2, CCL7, IL6, MMP1, MMP2 and MMP3 secretion by HDFs was determined by ELISA. All culture conditions were carried out at $37^{\circ} \mathrm{C}$ under $5 \% \mathrm{CO}_{2}$.

\section{Stimulation of HDFs by CM of M1 macrophages followed by stimulation with CM of M2 macrophages (switch)}

HDFs were cultured as described above. After overnight seeding in X-VIVO-10 medium the medium was replaced by CM of M1 macrophages for $24 \mathrm{~h}$ or $48 \mathrm{~h}$, with refreshment of the CM after $24 \mathrm{~h}$. After $24 \mathrm{~h}$ or $48 \mathrm{~h}$ the medium was replaced by $\mathrm{CM}$ of M2 macrophages or by $\mathrm{X}$-VIVO-10 medium (non-CM) for another $48 \mathrm{~h}$ or $96 \mathrm{~h}$, respectively (total culture time now $72 \mathrm{~h}$ and $144 \mathrm{~h}$, respectively); the $\mathrm{CM}$ or non-CM were refreshed every day. The HDFs were characterized by qRT-PCR.

\section{RNA isolation, cDNA synthesis and qRT-PCR}

Total RNA was isolated from the cells using the RNeasy Kit (Qiagen Inc., CA, USA) in accordance to the manufacturer's protocol. RNA concentration and purity were determined by UV spectrophotometry (NanoDrop Technologies, Wilmington, NC). For qRT-PCR analysis, total RNA was reverse transcribed using the First Strand cDNA synthesis kit (Fermentas UAB, Lithuania) in accordance to the manufacturer's protocol. Quantification of gene expression was performed using qRT-PCR analysis in a final reaction volume of $10 \mu \mathrm{l}$, consisting of $1 \times$ SYBR Green Supermix (Bio-Rad, Hercules, USA), $6 \mu \mathrm{M}$ forward primer, $6 \mu \mathrm{M}$ reverse primer (Table 2) and $5 \mathrm{ng}$ cDNA. Reactions were performed at $95^{\circ} \mathrm{C}$ for $15 \mathrm{sec}, 60^{\circ}$ $\mathrm{C}$ for $30 \mathrm{sec}, 72^{\circ} \mathrm{C}$ for $30 \mathrm{sec}$, for 40 cycles in a ViiA ${ }^{\mathrm{mm}} 7$ Real-Time PCR System (Applied Biosystems, CA, USA). Analysis of the data was performed using ViiA $7^{\text {mo }}$ RealTime PCR System Software v1.1 (Applied Biosystems, CA, USA).

\section{Enzyme-linked immunosorbent assay (ELISA)}

Determination of CCL2, CCL7, CCL18, IL6, MMP1, MMP2 and MMP3 protein levels were measured using DuoSet $^{\circ}$ ELISA Development kit (R\&D Systems, Minneapolis, USA) in accordance to manufacturer's protocol. Briefly, 96 wells plates (\#9018, Corning, Amsterdam, The Netherlands) were coated with Capture Antibody and incubated overnight at room temperature (RT). After incubation the plates were washed with $0.05 \%$ Tween-20 (Sigma-Aldrich, St. Louis,
Table 2 Overview of primers used for qRT-PCR analysis

\begin{tabular}{|c|c|c|}
\hline $\begin{array}{l}\text { Target } \\
\text { gene }\end{array}$ & Forward sequence & Reverse sequence \\
\hline ACTA2 & CTGTTCCAGCCATCCTTCAT & TCATGATGCTGTTGTAGGTGGT \\
\hline CCL18 & ATGGCCCTCTGCTCCTGT & AATCTGCCAGGAGGTATAGACG \\
\hline CCL2 & AGTCTCTGCCGCCCTTCT & GTGACTGGGGCATTGATTG \\
\hline CCL7 & ATGAAAGCCTCTGCAGCACT & TCTGTAGCAGCAGGTAGTTGAAGT \\
\hline CD14 & AGCTAAAGCACTTCCAGAGC & AGTTGTGGCTGAGGTCTAGG \\
\hline CD40 & GGTCTCACCTCGCTATGGTT & CAGTGGGTGGTTCTGGATG \\
\hline CD68 & GTCCACCTCGACCTGCTCT & CACTGGGGCAGGAGAAACT \\
\hline CLEC10A & AGGGTITCAAGCAGGAACG & AGGTGTGCCTTCTGCGTAGT \\
\hline COL1A1 & GCCTCAAGGTATTGCTGGAC & ACCTTGTTTGCCAGGTTCAC \\
\hline COL3A1 & CTGGACCCCAGGGTCTTC & CATCTGATCCAGGGTTTCCA \\
\hline GAPDH & AGCCACATCGCTCAGACAC & GCCCAATACGACCAAATCC \\
\hline IL $1 \mathrm{~B}$ & TACCTGTCCTGCGTGTTGAA & TCTTTGGGTAATTITTGGGATCT \\
\hline IL1R2 & TTCTGCCTTCACCCTTCAG & GGCACCTCAGGGCTACAG \\
\hline IL6 & ACTTGCCTGGTGAAAATCAT & CAGGAACTGGATCAGGACTT \\
\hline MMP1 & GCTAACCTTTGATGCTATAACTACGA & TTGTGCGCATGTAGAATCTG \\
\hline MMP14 & TACTTCCCAGGCCCCAAC & GCCACCAGGAAGATGTCATT \\
\hline MMP2 & CCCCAAAACGGACAAAGAG & CTTCAGCACAAACAGGTTGC \\
\hline MMP3 & CAAAACATATTCTITGTAGAGGACAA & TTCAGCTATTTGCTTGGGAAA \\
\hline MRC1 & ACACCAAAACCTGAGCCAAC & CCACCCATCTTCAGTAACTGGT \\
\hline TAGLN & CTGTTCCAGCCATCCTTCAT & TCATGATGCTGTTGTAGGTGGT \\
\hline TIMP1 & GAAGAGCCTGAACCACAGGT & CGGGGAGGAGATGTAGCAC \\
\hline YWHAZ & GATCCCCAATGCTTCACAAG & TGCTTGTTGTGACTGATCGAC \\
\hline
\end{tabular}

USA) in PBS and blocked with $1 \%$ bovine serum albumin (BSA) (Sanquin, Amsterdam, the Netherlands) in PBS for $1 \mathrm{~h}$. After washing, the plates were incubated with diluted sample or matched standards for $2 \mathrm{~h}$. The detection was performed using matched biotin conjugated antibodies followed by streptavidin-poly-horseradish peroxidase (Sanquin, Amsterdam, The Netherlands). The color reaction was performed with tetramethylbenzidine (TMB; SigmaAldrich, St. Louis, USA) in sodium acetate buffer, $\mathrm{pH}$ 6, containing $\mathrm{H}_{2} \mathrm{O}_{2}$ and stopped with $1 \mathrm{M} \mathrm{H}_{2} \mathrm{SO}_{4}$. The absorbance was measured using a microplate reader (VERSA max, Molecular Devices Inc., CA, USA). The detection limit for MMP2, MMP1, MMP3, CCL2, IL6, CCL7 and CCL18 was $312 \mathrm{pg} / \mathrm{ml}, 78 \mathrm{pg} / \mathrm{ml}, 15.6 \mathrm{pg} / \mathrm{ml}, 7.8 \mathrm{pg} / \mathrm{ml}, 4.7 \mathrm{pg} / \mathrm{ml}$ and $3.9 \mathrm{pg} / \mathrm{ml}$, respectively.

\section{Multiplex bead immunoassay}

Factors that were secreted by M1, M2 and unstimulated macrophages were determined by a multiplex bead immunoassay in accordance to manufacturer's protocol (Invitrogen Corporation, Carlsbad, USA). Briefly, beads that have defined spectral properties and are conjugated to protein-specific capture antibodies were added to a 96 well filter plate. After washing, the plate was incubated with sample or matched standards for $2 \mathrm{~h}$. The detection was performed using protein-specific biotinylated 
detector antibodies and streptavidin conjugated RPhycoerythrin. The beads were analyzed with the Luminex-100 detection system (Luminex, Austin, USA).

\section{Proteolytic activity assay}

MMP activity was determined in the CM of HDFs after $24 \mathrm{~h}$ of stimulation with CM derived of M1, M2 or unstimulated macrophages. The CM of the HDFs was mixed, in a black 96 flat bottom plate, with prewarmed assay buffer containing 0.1 M 4-(2-hydroxyethyl)-1piperazineethanesulfonic acid (HEPES), $20 \mathrm{mM} \mathrm{CaCl}_{2}$, $0,1 \%$ Brij-35, pH 7.0 and $10 \mu \mathrm{M}$ OmniMMP ${ }^{\text {тм }}$ fluorogenic substrate (BML-P126, Enzo Life Sciences, Antwerpen, Belgium). The fluorescent intensity was measured using a fluorescence plate reader (BIO-TEK FL600, BIO-TEK instruments, Inc., Winooski, USA) after $20 \mathrm{~h}$ of incubation at $37^{\circ} \mathrm{C}$.

\section{Immunofluorescent stainings for ACTA2 and MK167 on stimulated adult human dermal fibroblasts}

After $24 \mathrm{~h}$ and $144 \mathrm{~h}$ of culture, HDFs were washed twice with PBS and fixed in 2\% paraformaldehyde (PFA) at RT for $10 \mathrm{~min}$. Fixed cells were incubated with $0.5 \%$ Triton X100 (Merck, Darmstadt, Germany) in PBS for 3 min at RT. After washing with PBS the cells were incubated with (1) mouse-anti-human ACTA2 (M0851, Dako, Glosstrup, Denmark) (1:100) or (2) rabbit-anti-human MKI67 (MONOSAN ${ }^{\oplus}$, Uden, The Netherlands) (1:500) diluted in PBS containing $1 \%$ BSA for $1 \mathrm{~h}$ at RT. After three washes with PBS, cells were incubated with biotinylated (1) goatanti-mouse IgG2a-biotin (SouthernBiotech, Alabama, USA) (1:100), or (2) goat-anti-rabbit-FITC (SouthernBiotech, Alabama, USA) (1:100) diluted in PBS containing 2\% normal human serum (NHS) for $30 \mathrm{~min}$ at room temperature. The cells were subsequently washed three times with PBS and incubated with streptavidine-CY3 (Invitrogen, Grand Island, USA) (1:100) in PBS containing 1\% BSA, 2\% NHS and DAPI (1:5000) for 30 min. After three washes with PBS the slides were mounted in Citifluor (Agar Scientific, Essex, UK) and examined by immunofluorescent microscopy using a Leica DMRA microscope equipped with a Leica DFC350FX digital camera and Leica Application Suite (LAS) software (all Leica Microsystems, Wetzlar, Germany).

\section{Collagen type I deposition by HDFs after stimulation with CM of M1, M2 or unstimulated macrophages}

After $72 \mathrm{~h}$ and $144 \mathrm{~h}$ of culture, HDFs were washed twice with PBS and fixed in 2\% PFA at RT for $10 \mathrm{~min}$. Fixed cells were incubated at RT with (1) mouse-anti-human collagen type I (COL I) (1:100) (ab90395, Abcam, Cambridge, UK) diluted in PBS containing 1\% BSA for $1 \mathrm{~h}$. The HDFs were washed three times with PBS, followed by incubation with goat-anti-mouse IgG1-biotin (SouthernBiotech, Alabama, USA) (1:100) diluted in 1\% BSA in PBS for $30 \mathrm{~min}$. The cells were subsequently washed three times with PBS and incubated with streptavidine-CY3 (1:100) in PBS containing 1\% BSA, 2\% NHS and DAPI (1:5000) for $30 \mathrm{~min}$. After three washes with PBS the slides were mounted in Citifluor and examined by immunofluorescent microscopy using a Leica DMRA microscope.

\section{Collagen gel contraction}

Collagen gels were prepared by mixing X-VIVO-10 medium, $1 \mathrm{M} \mathrm{NaOH}, 10 \times$ PBS, 0.2 M HEPES and collagen I (BD Biosciences, Franklin Lakes, NJ USA). The final concentration was $5.2 \mathrm{mM} \mathrm{NaOH}, 1 \times \mathrm{PBS}, 2 \mathrm{mM}$ HEPES, $2.4 \mathrm{mg} / \mathrm{ml}$ of collagen I in X-VIVO-10 medium. HDFs were added in a concentration of 200.000 cells $/ \mathrm{ml}$ and $500 \mu \mathrm{l}$ of this mixture was pipetted into a well of a 24-well culture plate. Polymerization of the solution occurred within $1 \mathrm{~h}$ at $37^{\circ} \mathrm{C}$ under $5 \% \quad \mathrm{CO}_{2}$. After polymerization $\mathrm{CM}$ of $\mathrm{M} 1, \mathrm{M} 2$ or unstimulated macrophages was added. As control complete X-VIVO medium supplemented with $10 \mathrm{ng} / \mathrm{ml}$ TGFB1 (PeproTech EC Ltd, London, UK) was used. The CM and medium supplemented with TGFB1 was refreshed every day and the cells were cultured at $37^{\circ} \mathrm{C}$ under $5 \%$ $\mathrm{CO}_{2}$. After 5 days the gels were gently released and contractile force was analyzed by measuring the gel diameter at $8 \mathrm{~h}$ after release using a flatbed scanner (Hewlett-Packard Company, Palo Alto, USA) Data are expressed as the percentage of area compared to the initial gel area.

\section{Statistics}

All data are represented as means \pm standard error of the mean of at least three independent experiments and were analyzed by Graph-Pad Prism Version 5 for Macintosh (GraphPad Software, Inc., La Jolla, CA, USA) either by one-way ANOVA followed by Tukey's post hoc analysis, or by two-way ANOVA followed by Bonferroni post hoc analysis. Values of $P<0.05$ were considered to be statistically significant.

\section{Abbreviations}

ACTA2: Alpha-actin-2; BSA: Bovine serum albumin; CCL: Chemokine (C-C motif) ligand; CLEC10A: C-type lectin domain family 10, member A; CM: Conditioned medium; COL1A1: Collagen type I; COL3A1: Collagen type III; CXCL: Chemokine (C-X-C motif) ligand; ECM: Extracellular matrix; FBS: Fetal bovine serum; FGF2: Fibroblast growth factor 2; HDFs: Human primary dermal fibroblasts; IFNG: Interferon gamma; IL: Interleukin;

LPS: Lipopolysaccharides; M-CSF: Macrophage colony-stimulating factor; M1: Classically activated macrophages; M2: Alternatively activated macrophages; MKI67: Nuclear protein Ki-67; MMP: Matrix metalloproteinase; MRC1: Mannose receptor, C type 1; NHS: Normal human serum; PBMCs: Peripheral blood mononuclear cells; PBS: Phosphate buffered saline; PFA: Paraformaldehyde; qRT-PCR: Quantitative Reverse Transcription polymerase chain reaction; TAGLN: Transgelin; TCPS: Tissue culture polystyrene plates; TGFB1: Transforming growth factor beta 1; TIMP1: Tissue inhibitor of metalloproteinases -1; TLR4: Toll-like receptor 4;

TMB: Tetramethylbenzidine; TNF: Tumor necrosis factor; YWHAZ: Tyrosine 3-monooxygenase/tryptophan 5-monooxygenase activation protein, zeta polypeptide. 


\section{Competing interests}

The authors declare that they have no competing interests.

\section{Authors' contributions}

DTAP designed research, performed experiments, analyzed data, interpreted data and wrote the manuscript. NAH designed research, performed experiments, interpreted data and edited the manuscript. MS contributed to preliminary experiments. JAK and SdR performed experiments and edited the manuscript. R.A.B. supervised the work, interpreted the data, and edited the manuscript. All authors read and approved the final manuscript.

\section{Acknowledgements}

The authors gratefully acknowledge the financial support of the Netherlands Institute for Regenerative Medicine (NIRM).

\section{Received: 7 November 2012 Accepted: 11 April 2013}

Published: 19 April 2013

\section{References}

1. Stramer BM, Mori R, Martin P: The inflammation-fibrosis link? A Jekyll and Hyde role for blood cells during wound repair. J Invest Dermato/ 2007, 127(5):1009-1017.

2. Mahdavian Delavary B, van der Veer WM, van Egmond M, Niessen FB, Beelen RH: Macrophages in skin injury and repair. Immunobiology 2011, 216(7):753-762.

3. Eming SA, Hammerschmidt M, Krieg T, Roers A: Interrelation of immunity and tissue repair or regeneration. Semin Cell Dev Biol 2009, 20(5):517-527.

4. Duffield JS, Forbes SJ, Constandinou CM, Clay S, Partolina M, Vuthoori S, Wu S, Lang R, Iredale JP: Selective depletion of macrophages reveals distinct, opposing roles during liver injury and repair. J Clin Invest 2005, 115(1):56-65.

5. Singer AJ, Clark RAF: Cutaneous Wound Healing. N Engl J Med 1999, 341(10):738-746.

6. Gurtner GC, Werner S, Barrandon Y, Longaker MT: Wound repair and regeneration. Nature 2008, 453(7193):314-321.

7. Gabbiani G: The myofibroblast in wound healing and fibrocontractive diseases. J Pathol 2003, 200(4):500-503.

8. Meran S, Steadman R: Fibroblasts and myofibroblasts in renal fibrosis. Int J Exp Pathol 2011, 92(3):158-167.

9. Sarrazy V, Billet F, Micallef L, Coulomb B, Desmoulière A: Mechanisms of pathological scarring: role of myofibroblasts and current developments. Wound Repair Regen 2011, 19:s10-s15.

10. Gordon S, Taylor PR: Monocyte and macrophage heterogeneity. Nat Rev Immunol 2005, 5(12):953-964.

11. Mosser DM, Edwards JP: Exploring the full spectrum of macrophage activation. Nat Rev Immunol 2008, 8(12):958-969.

12. Murray PJ, Wynn TA: Obstacles and opportunities for understanding macrophage polarization. J Leukoc Biol 2011, 89(4):557-563.

13. Wynn TA, Barron L: Macrophages: master regulators of inflammation and fibrosis. Semin Liver Dis 2010, 30(3):245-257.

14. Duffield JS: The inflammatory macrophage: a story of Jekyll and Hyde. Clin Sci (Lond) 2003, 104(1):27-38.

15. Martin P, Leibovich SJ: Inflammatory cells during wound repair: the good, the bad and the ugly. Trends Cell Biol 2005, 15(11):599-607.

16. Gordon S: Alternative activation of macrophages. Nat Rev Immunol 2003, 3(1):23-35.

17. Popova A, Kzhyshkowska J, Nurgazieva D, Goerdt S, Gratchev A: Pro- and anti-inflammatory control of M-CSF-mediated macrophage differentiation. Immunobiology 2011, 216(1-2):164-172.

18. Barrientos S, Stojadinovic O, Golinko MS, Brem H, Tomic-Canic M: PERSPECTIVE ARTICLE: Growth factors and cytokines in wound healing. Wound Repair Regen 2008, 16(5):585-601.

19. Ma F, Li Y, Jia L, Han Y, Cheng J, Li H, Qi Y, Du J: Macrophage-Stimulated Cardiac Fibroblast Production of IL- 6 Is Essential for TGF $\beta / S m a d$ Activation and Cardiac Fibrosis Induced by Angiotensin II. PLoS One 2012, 7(5):e35144.

20. Atamas SP: Complex cytokine regulation of tissue fibrosis. Life Sci 2002, 72(6):631-643.

21. Wynn T: Cellular and molecular mechanisms of fibrosis. J Pathol 2008, 214(2):199-210.

22. Prasse A, Pechkovsky DV, Toews GB, Jungraithmayr W, Kollert F, Goldmann T, Vollmer E, Müller-Quernheim J, Zissel G: A Vicious Circle of Alveolar
Macrophages and Fibroblasts Perpetuates Pulmonary Fibrosis via CCL18. Am J Respir Crit Care Med 2006, 173(7):781-792.

23. Bellón T, Martínez V, Lucendo B, del Peso G, Castro MJ, Aroeira LS, Rodríguez-Sanz A, Ossorio M, Sánchez-Villanueva R, Selgas R, Bajo MA: Alternative activation of macrophages in human peritoneum: implications for peritoneal fibrosis. Nephrol Dial Transplant 2011 26(9):2995-3005.

24. Stout RD, Suttles J: Functional plasticity of macrophages: reversible adaptation to changing microenvironments. J Leukoc Biol 2004, 76(3):509-513.

25. Stout RD, Jiang C, Matta B, Tietzel I, Watkins SK, Suttles J: Macrophages Sequentially Change Their Functional Phenotype in Response to Changes in Microenvironmental Influences. J Immuno/ 2005, 175(1):342-349.

26. Gratchev A, Kzhyshkowska J, Kothe K, Muller-Molinet I, Kannookadan S, Utikal J, Goerdt S: Mphi1 and Mphi2 can be re-polarized by Th2 or Th1 cytokines, respectively, and respond to exogenous danger signals. Immunobiology 2006, 211(6-8):473-486.

27. Ploeger DTA, van Putten SM, Koerts JA, van Luyn MJA, Harmsen MC: Human macrophages primed with angiogenic factors show dynamic plasticity, irrespective of extracellular matrix components. Immunobiology 2012, 217(3):299-306.

28. Khallou-Laschet J, Varthaman A, Fornasa G, Compain C, Gaston AT, Clement M, Dussiot M, Levillain O, Graff-Dubois S, Nicoletti A, Caligiuri G: Macrophage plasticity in experimental atherosclerosis. PLOS One 2010, 5(1):e8852.

29. Harel-Adar T, Mordechai TB, Amsalem Y, Feinberg MS, Leor J, Cohen S: Modulation of cardiac macrophages by phosphatidylserine-presenting liposomes improves infarct repair. Proc Natl Acad Sci USA 2011, 108(5):1827-32.

30. Zickus C, Kunkel SL, Simpson K, Evanoff H, Glass M, Strieter RM, NW: Differential regulation of $\mathrm{C}-\mathrm{C}$ chemokines during fibroblast-monocyte interactions: adhesion vs. inflammatory cytokine pathways. Mediat Inflamm 1998, 7(4):269-274.

31. Song E, Ouyang N, Hörbelt M, Antus B, Wang M, Exton MS: Influence of Alternatively and Classically Activated Macrophages on Fibrogenic Activities of Human Fibroblasts. Cell Immunol 2000, 204(1):19-28.

32. Hao L, Okada H, Kanno Y, Inoue T, Kobayashi T, Watanabe $Y$, Strutz F, Müller GA, Suzuki H: Direct Contact between Human Peripheral Blood Mononuclear Cells and Renal Fibroblasts Facilitates the Expression of Monocyte Chemoattractant Protein-1. Am J Nephrol 2003, 23(4):208-213.

33. Steinhauser ML, Kunkel SL, Hogaboam CM, Evanoff H, Strieter RM, Lukacs NW: Macrophage/fibroblast coculture induces macrophage inflammatory protein-1alpha production mediated by intercellular adhesion molecule1 and oxygen radicals. J Leukoc Biol 1998, 64(5):636-641.

34. Holt DJ, Chamberlain LM, Grainger DW: Cell-cell signaling in co-cultures of macrophages and fibroblasts. Biomaterials 2010, 31(36):9382-9394.

35. Zhu Y, Liu X, Skold CM, Wang H, Kohyama T, Wen FQ, Ertl RF, Rennard SI: Collaborative interactions between neutrophil elastase and metalloproteinases in extracellular matrix degradation in threedimensional collagen gels. Respir Res 2001, 2(5):300-305.

36. Zhu Y, Skold CM, Liu X, Wang H, Kohyama T, Wen FQ, Ertl RF, Rennard SI: Fibroblasts and monocyte macrophages contract and degrade threedimensional collagen gels in extended co-culture. Respir Res 2001, 2(5):295-299.

37. Daley JM, Brancato SK, Thomay AA, Reichner JS, Albina JE: The phenotype of murine wound macrophages. J Leukoc Biol 2010, 87(1):59-67.

38. Stables MJ, Shah S, Camon EB, Lovering RC, Newson J, Bystrom J, Farrow S, Gilroy DW: Transcriptomic analyses of murine resolution-phase macrophages. Blood 2011, 118(26):e192-e208.

39. van Putten SM, Ploeger DTA, Popa ER, Bank RA: Macrophage phenotypes in the collagen-induced foreign body reaction in rats. Acta Biomater 2013, 9(5):6502-6510.

40. Sweet MJ, Hume DA: CSF-1 as a regulator of macrophage activation and immune responses. Arch Immunol Ther Exp (Warsz) 2003, 51(3):169-177.

41. Martinez FO, Gordon S, Locati M, Mantovani A: Transcriptional Profiling of the Human Monocyte-to-Macrophage Differentiation and Polarization: New Molecules and Patterns of Gene Expression. J Immunol 2006, 177(10):7303-7311. 
42. Gill SE, Parks WC: Metalloproteinases and their inhibitors: Regulators of wound healing. Int J Biochem Cell Biol 2008, 40(6-7):1334-1347.

43. Shah JM, Omar E, Pai DR, Sood S: Cellular events and biomarkers of wound healing. Indian J Plast Surg 2012, 45(2):220-228.

44. Wynes MW, Frankel SK, Riches DWH: IL-4-induced macrophage-derived IGF-I protects myofibroblasts from apoptosis following growth factor withdrawal. J Leukoc Biol 2004, 76(5):1019-1027.

doi:10.1186/1478-811X-11-29

Cite this article as: Ploeger et al:: Cell plasticity in wound healing: paracrine factors of $\mathrm{M} 1 / \mathrm{M} 2$ polarized macrophages influence the phenotypical state of dermal fibroblasts. Cell Communication and Signaling 2013 11:29.

\section{Submit your next manuscript to BioMed Central and take full advantage of:}

- Convenient online submission

- Thorough peer review

- No space constraints or color figure charges

- Immediate publication on acceptance

- Inclusion in PubMed, CAS, Scopus and Google Scholar

- Research which is freely available for redistribution 